\title{
A large cellular angiofibroma of the male pelvis presenting with obstructive voiding: A case report and review of the literature
}

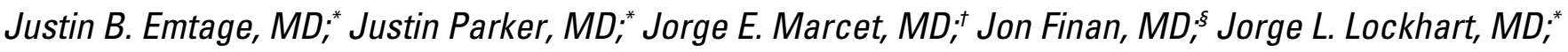 \\ David J. Hernandez, MD*
}

*Department of Urology, University of South Florida, Tampa, FL; 'Division of Colon and Rectal Surgery, University of South Florida, Tampa, FL; §Division of Pathology, University of South Florida, Tampa, FL

Cite as: Can Urol Assoc J 2013;7(5-6):e373-5. http://dx.doi.org/10.5489/cuaj.1222 Published online May 13, 2013.

\section{Abstract}

Cellular angiofibromas (CAF) are rare, benign soft-tissue tumours. The diagnosis of CAF is important given the heavy resemblance to other tumours. Herein, we describe a case of a rapidly growing, very large $(13.5 \mathrm{~cm})$ CAF located in the deep pelvis of a middleaged male who presented with difficulty voiding.

\section{Introduction}

Cellular angiofibromas (CAF) are rare, benign soft-tissue tumours first described by Nucci and colleagues in $1997 .{ }^{1}$ CAF share pathological features of angiomyofibroblastoma and aggressive angiomyxoma (AAM), but do not fall into either category. The masses are well-circumscribed, typically less than $3.0 \mathrm{~cm}$ and show marked female predominance. In 1998, Laskin and colleagues reported 11 of these tumours in male genitalia, ${ }^{2}$ and since then there have been only a few case reports. Most have been found in women, primarily in the vulva. ${ }^{3-5}$ In males, most are found in the scrotum and inguinal region, averaging about 5 to $6 \mathrm{~cm}$ in size., ${ }^{2,3}$ The diagnosis of CAF is important given the heavy resemblance to other tumours, such as AAM, which is known to have a very high rate of local recurrence. ${ }^{4}$ Herein, we describe the case of a rapidly growing, very large $(13.5 \mathrm{~cm})$ CAF located in the deep pelvis of a middle-aged male who presented with difficulty voiding.

\section{Case presentation}

A 58-year-old man initially presented with right groin/pelvic pain radiating down into his scrotum, as well as decreased urinary flow and decreased ejaculation. Due to refractory symptoms, a computed tomography (CT) scan of the abdo- men and pelvis was done which showed a $7 \times 7 \times 5-\mathrm{cm}$ mass to the right of the prostate extending down to the bulbar urethra. Prior attempts at both transurethral drainage and transperineal aspiration were unsuccessful and he was then referred to our clinic. A pelvic magnetic resonance imaging (MRI) revealed substantial growth; a 11-cm wellcircumscribed lesion abutting the rectum and displacing the urinary bladder and prostate proximally (Fig. 1, Fig. 2). Biopsies showed a benign stromal tumour of genitourinary origin. Resection was recommended via combined abdominal/perineal approach with colorectal surgery and urology.

Exploratory laparotomy showed a large encapsulated mass occupying the entirety of the lower pelvis. The mass was dissected off of the prostate with relative ease, but was more difficult distally owing to dense adherence to a $3-\mathrm{cm}$ portion on the anterior surface of the bulbar urethra. The mass was carefully freed from the rectum through the perineal incision. Ultimately, the intact mass in its entirety was removed with no evidence of residual disease. The specimen was sent to pathology and was read as a large benign spindle cell tumour mostly consistent with a CAF.

\section{Gross description}

This was an encapsulated, well-circumscribed mass with a thin fibrous capsule. It was elongated and measured $13.5 \times 7.4 \times 3.7 \mathrm{~cm}$ (Fig. 3). The mass felt rubbery and sectioning revealed a gelatinous, tan-pink to grey surface that was focally trabeculated.

\section{Microscopic description}

The mass consisted of loosely arranged bland spindle shaped cells in a myxoid stroma (Fig. 4). Abundant partially hyalinized vessels were interspersed throughout the lesion. Dense collagen bundles, as well as thin filaments, were also evident. There was no significant pleomorphism. 


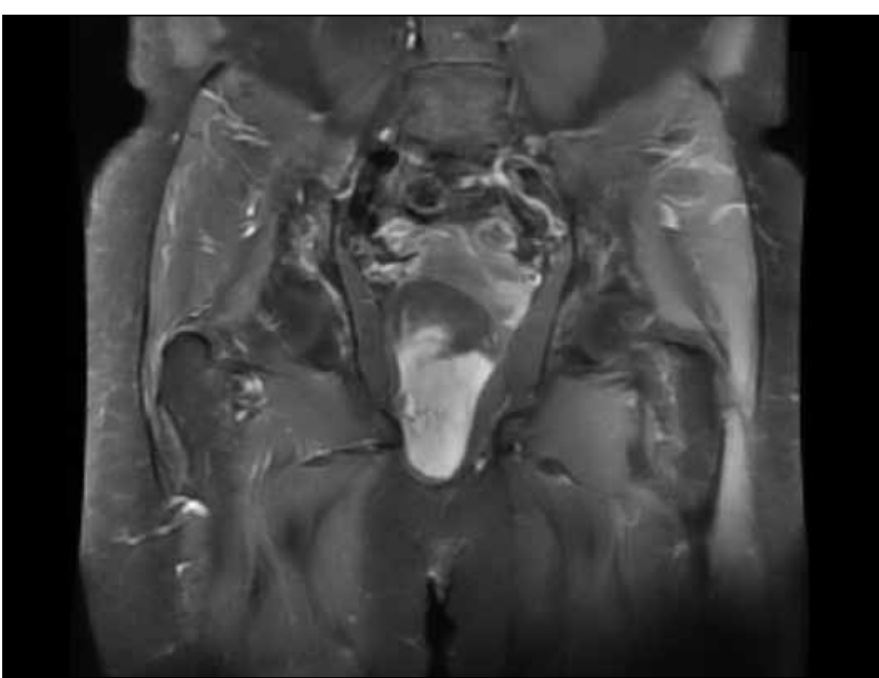

Fig. 1. Coronal section of the T1 weighted fat suppressed post-gadolinium magnetic resonance imaging of the pelvis showing both cystic elements superiorly and solid elements inferiorly with intense enhancement following IV contrast administration.

\section{Discussion}

CAFs are rare benign mesenchymal tumours normally found in women; it is rarely found in men. ${ }^{3}$ The median age at diagnosis is the mid 50 s, with a size typically about 5 to $6 \mathrm{~cm} \cdot{ }^{1-3,5,6}$ There are only 2 reported cases measuring more than $10 \mathrm{~cm}$. CAFs are mainly found in the scrotum and inguinal region, but have also been reported in the knee, upper eyelid, oral and perianal region. ${ }^{3,7,8}$ Grossly, they are well-circumscribed superficial lesions with a thin fibrous capsule. Histopathologically, they are moderately cellular with prominent hyalinized round vessels and a uniform distribution of bland spindle cells. Approximately $60 \%$ express CD $34 ; 35 \%$ to $55 \%$ express estrogen receptor/progesterone receptor (ER/PR) and 10\% express desmin. S-100 is uniformly non-reactive. ${ }^{1,2}$

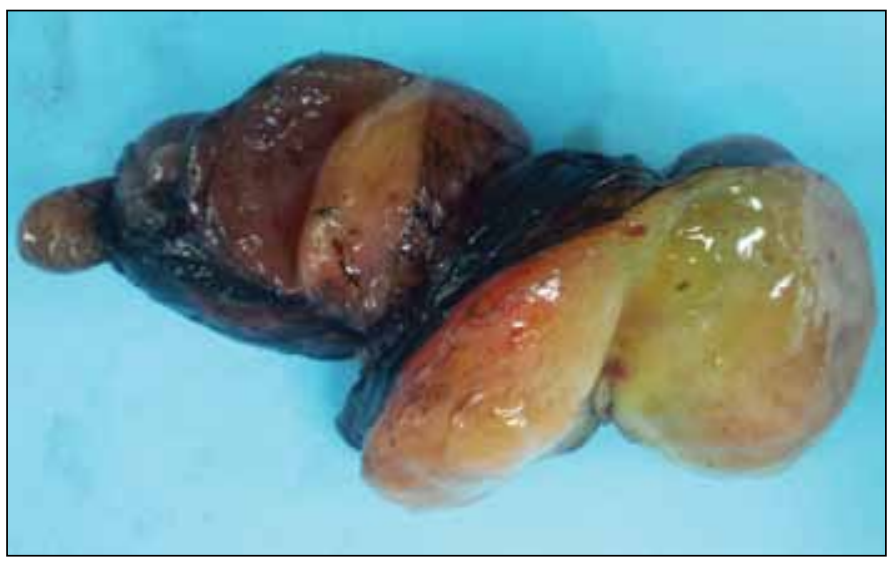

Fig. 3. The mass as it appeared on removal. A large encapsulated, wellcircumscribed mass measuring $13.5 \mathrm{~cm}$ on its longest axis.

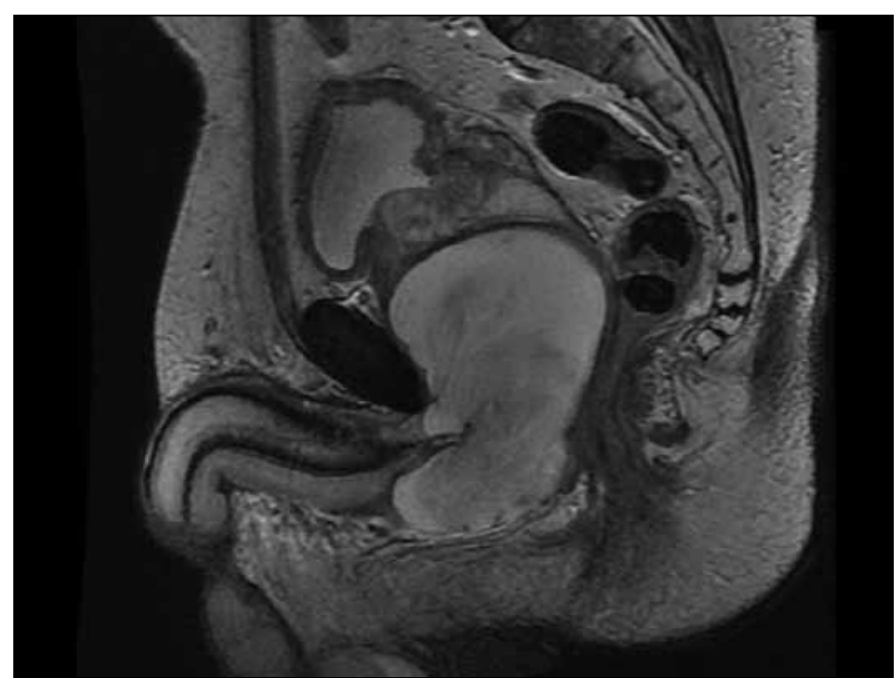

Fig. 2. Saggital section of the $\mathrm{T} 2$ weighted magnetic resonance imaging of the pelvis showing superior displacement of the prostate, posterior mass effect on the rectum and inferior extension to the base of the penis.

Our mass showed immunoreactivity for CD34, desmin and ER/PR, but was non-reactive for S100, smooth muscle actin, pan keratin and CD117. This case is unique as it is one of the first cases of CAF found deep in the pelvis, extending to the perineum, abutting the prostate and rectum, and densely adherent to the urethra. The fact that it was about $13.5 \mathrm{~cm}$ on excision also shows that tumours in this location can grow as large as any previously reported CAF. ${ }^{1,2}$ This tumour also underwent rapid growth, expanding by almost $50 \%$ over a few months. This has not been previously described and bolsters the current practice of surgical excision. ${ }^{3,9}$

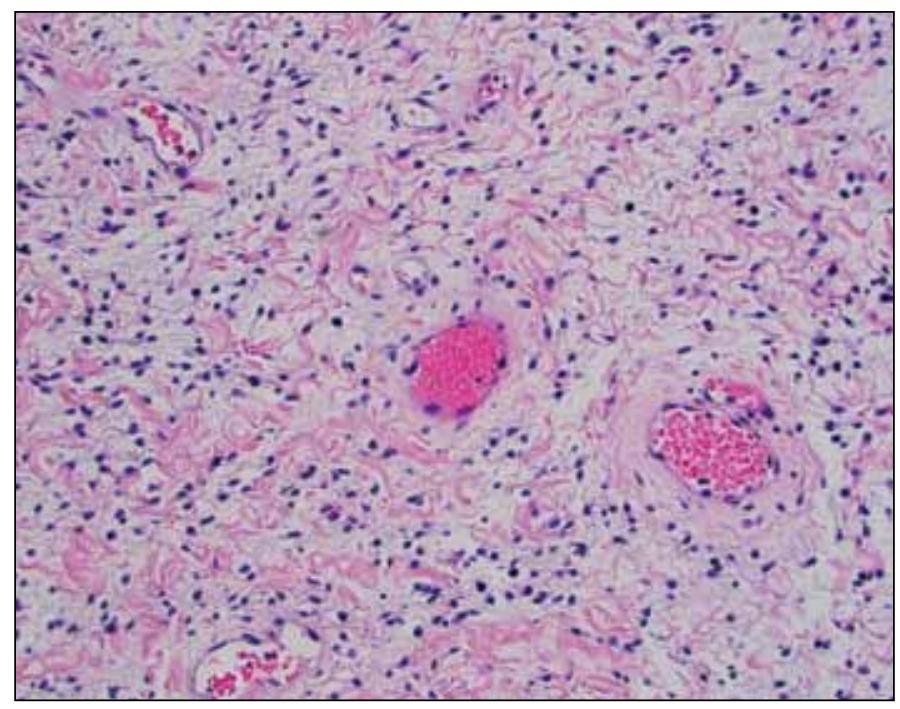

Fig. 4. Histopathology demonstrates loosely organized bland spindle shaped cells in a watery background. Prominent thick walled blood vessels are scattered throughout the lesion with fine collagenous fibers. 


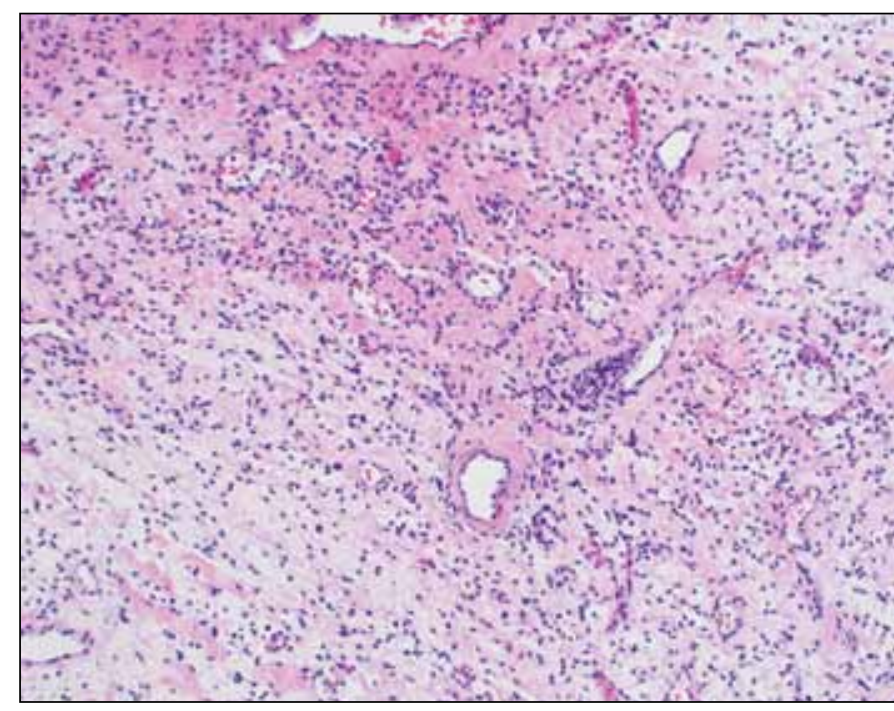

Fig. 5. Histopathology demonstrates loosely organized bland spindle shaped cells in a watery background. Prominent thick walled blood vessels are scattered throughout the lesion with fine collagenous fibers.

Previous reports note scrotal or inguinal pain as the presenting sign of CAF, but our case appears to be the first describing dysuria and obstructive voiding. As such, this case highlights the possible benefit of pelvic imaging for treatment of refractory symptoms of this nature. The most important consideration is correctly distinguishing CAF from AAM. AAMs are locally infiltrating tumours affecting the pelvic or perineal soft tissue with local recurrence rates up to $30 \%$ despite wide local excision. ${ }^{10,11}$ Conversely, CAFs are definitively treated by simple excision and no clear recurrence has ever been noted. 6,12,13 Therefore, removal and clinical follow-up is an adequate long-term plan and our patient was still disease-free at the 9-month follow up.

Histopathologically, these tumours are of mesenchymal stem cell origin and do not contain differentiated tissue. ${ }^{12}$ This was the case for our tumour, which contained no evidence of prostatic, rectal or urethral tissue. This is interesting given the close approximation to these structures and the urethral adherence found during surgical dissection. Additionally, this tumour did not show any cellular atypia or sarcomatous transformation. The impact of this finding is debatable, but a recent study with a 14-month follow-up has not shown either of these features to be associated with recurrence or metastasis. ${ }^{6}$

\section{Conclusion}

We present a large CAF of the male deep pelvis found with the workup of refractory obstructive voiding along with pel- vic pain. The diagnosis is made with imaging showing a well-circumscribed hypervascular mass containing fat; histology showing prominent hyalinized round vessels and a uniform distribution of bland spindle cells, and gross exam showing an encapsulated rubbery mass. Given the rapid growth and lack of recurrence or metastasis, simple surgical excision is the treatment of choice for symptomatic lesions.

Competing interests: None declared.

This paper has been peer-reviewed.

\section{References}

1. Nucci MR, Granter SR, Fletcher CDM. Cellular angiofibroma: a benign neoplasm distinct from angiomyofibroblastoma and spindle cell lipoma. Am J Surg Pathol 1997;21:636-44. http://dx.doi. org/10.1097/00000478-199706000-00002

2. Laskin WB, Fetsch JF, Mostofi FK. Angiomyofibroblastoma like tumor of the male genital tract; analysis of 11 cases with comparison to female angiomyofibroblastoma and spindle cell lipoma. Am I Surg Pathol 1998;22:6-16. http://dx.doi.org/10.1097/00000478-199801000-00002

3. Flucke $\mathrm{U}$, van Krieken JHJM, Mentzel T. Cellular angiofibroma: analysis of 25 cases emphasizing its relationship to spindle cell lipoma and mammary-type myofibroblastoma. Modern Pathol 2011;24:82-9. http://dx.doi.org/10.1038/modpathol.2010.170

4. Fletcher CDM, Tsang WY, Fisher C, et al. Angiomyofibroblastoma of the vulva; a benign neoplasm distinct from aggressive angiomyxoma. Am J Surg Pathol 1992;16:373-82. http://dx.doi. org/10.1097/00000478-199204000-00006

5. McCluggage WG, Ganesan R Hirschowitz L, et al. Cellular angiofibroma and related fibromatous lesions of the vulva: report of a series of cases with a morphological spectrum wider than previously described. Histopathology 2004;45:360-8. http://dx.doi.org/10.1111/i.1365-2559.2004.01923.x

6. Chen E, Fletcher CDM. Cellular angiofibroma with atypia or sarcomatous transformation: Clinicopathologic analysis of 13 cases. Am I Surg Pathol 2010;34:707-14.

7. Eversole LR. Cellular angiofibroma of oral mucosa: report of two cases. Head Neck Pathol 2009;3:136-9. http://dx.doi.org/10.1007/s12105-009-0112-7

8. McMenamin ME, Fletcher CDM. Mammary-type myofibroblastoma of soft tissue. A tumor closely related to spindle cell lipoma. Am J Surg Pathol 2001;25:1022-9. http://dx.doi.org/10.1097/00000478200108000-00006

9. Kandil DH, Kida M, Laub DR, et al. Sarcomatous transformation in a cellular angiofibroma: a case report. J Clin Pathol 2009;62:945-7. http://dx.doi.org/10.1136/icp.2009.067124

10. Ito M, Yamaoka H, Sano K, et al. Angiomyotibroblastoma of the male inguinal region. Arch Pathol Lab Med 2000;124:1679-81.

11. Tsang WJ, Chan JK, Lee KC, et al. Aggressive angiomyxoma. A report of four cases occurring in men. Am J Surg Pathol 1992;16:1059-65. http://dx.doi.org/10.1097/00000478-199211000-00004

12. Lee SH, Yang JW, Do JM, et al. Angiomyofibroblastoma-like tumor of the scrotum. Korean J Urol 2010;51:365-7. http://dx.doi.org/10.4111/kju.2010.51.5.365

13. Miyaiima K, Hasegawa S, Oda Y, et al. Angiomyofibroblastoma-like tumor (cellular angiofibroma) in the male inguinal region. Radiat Med 2007;25:173-7. http://dx.doi.org/10.1007/s1 1604-006-0114-2

Correspondence: Dr. Justin B. Emtage, Department of Urology, University of South Florida, Tampa, Florida 33606; jemtage@health.usf.edu; jbemtage@bu.edu 